\title{
Recent doctoral theses (biochemistry, biology and biophysics) in Lithuania
}

Prepared by Indre LIPATOVA

\section{LIPASE SELECTION AND APPLICATION FOR FATTY ACID ESTER SYNTHESIS}

\section{Dovilè Šinkūnienè}

\section{Scientific supervisor:}

dr. Vida Bendikienè,

Vilnius University

The dissertation defended:

7 February 2014
Lipases are a widely researched enzyme group because of their ability to catalyze a wide range of synthesis reactions. The aim of this doctoral thesis was to study and optimize fatty acid ester synthesis using lipases. The influence of enzyme choice, its preparation (immobilization), choice of substrates and reaction conditions on fat hydrolysis, biodiesel and phenethyloctanoate (flavour ester) synthesis reaction course and yield were studied. Enterobacter aerogenes lipase, which was developed in Lithuania, was immobilized and its properties were determined for the first time. Commercial lipases were used for hydrolysis and synthesis reactions, the influence of reaction parameters was determined using response surface methodology, and so the yield was optimized. Silica gel was found to be a promising reaction additive for acyl group migration catalysis in biodiesel synthesis reaction. Different lipase specificities towards different acylglycerol classes and regioisomers varied greatly; on the basis of this knowledge two-step biodiesel synthesis catalysis was proposed. 


\section{RESPONSES OF MOUSE EMBRYO SENSORY NEURONS TO SEMAPHORIN 3A: SIGNALING PATHWAY AND REGENERATION}

\section{Andrius Kaselis}

Scientific supervisor:

prof. dr. Saulius Šatkauskas,

Vytautas Magnus University

The dissertation defended:

8 May 2014
The aim of this study was to evaluate the influence of NGF and cytosolic calcium on Sema3A-induced effects on sensory DRG neuron regeneration. During development and regeneration of the nervous system (NS) axons form functional junctions with innervated tissues. To form these junctions the axons are guided through their growth cones by attractive and repulsive factors that are expressed by the cells along the growth pathway. Principal components involved in axon pathfinding are attractive neurotrophic factors (such as nerve growth factor - NGF) and repulsive semaphorin class guidance molecules (such as semaphorin $3 \mathrm{~A}-$ Sema3A). In our research we have used the fifteenth day (E15) mouse embryo dorsal root ganglia (DRG) sensory neurons to determine effects of Sema3A on axon regeneration in vitro. Moreover, we have evaluated the impact of NGF and $\mathrm{Ca}^{2+}$ channel activity on the Sema3A dependent regeneration process guided by axon growth cones. We have found that the increase of NGF concentration does not impact growth cone responses to Sema3A but promotes axon elongation suppressed by Sema3A. We have also showed that growth cone collapse in response to Sema3A is dependent on increase of $\mathrm{Ca}^{2+}$ concentration in growth cones but not in the axons or bodies of neurons. Finally, we have for the first time shown that the Sema3A dependent increase of $\mathrm{Ca}^{2+}$ concentration in sensory neuron axon growth cones is mediated through R-type (Cav2.3) calcium channels. 


\section{SYNTHESIS OF POLYHYDROXYLIC COMPOUNDS BY BIOCATALYTIC}

METHODS

\section{Jonita Stankevičiūtè}

Scientific supervisor:

dr. Rolandas Meškys,

Vilnius University

The dissertation defended:

22 September 2014
In this study, the process of dihydroxyacetone phosphate production was improved by creating the unique reactor, which eliminated hydrogen peroxide. Moreover, the stereoselectivity and substrate specificity of PQQ-dependent $\mathrm{ADH}$ from Pseudomonas putida HK5, and NADPH-dependent short chain dehydrogenase / reductase TpdE from Rhodococcus jostii TMP1 were investigated. The potential of these enzymes as efficient biocatalysts for the production of chiral alcohols was demonstrated. In addition, free and alginate gel-entrapped cells of Burkholderia sp. MAK1 were studied as a whole cell biocatalyst for the synthesis of hydroxylated N-heterocyclic compounds. In total, 73 out of 110 tested compounds were transformed by Burkholderia sp. MAK1. The analysis of the products revealed that the hydroxylation was regioselective. Thus, the cells of Burkholderia sp. MAK1 can be applicable for the regioselective synthesis of pyridinols. 


\section{COMPUTATIONAL ANALYSIS OF DNA REPLICATION PROTEINS IN \\ DOUBLE-STRANDED DNA VIRUSES}

\section{Darius Kazlauskas}

\section{Scientific supervisor:}

dr. Česlovas Venclovas,

Vilnius University

The dissertation defended:

4 December 2014
Using current state-of-the-art computational methods we identified and characterized replication proteins (DNA polymerases, processivity factors, clamp loaders, primases, helicases, single-stranded DNA binding proteins, primer removal proteins, DNA ligases and topoisomerases) and analyzed their distribution patterns in genomes of dsDNA viruses. The analysis revealed dependency between DNA replicase components (DNA polymerases, processivity factors, clamp loaders) and the viral genome size. We found that small viruses $(<40 \mathrm{kbp})$ used protein-primed DNA replication or relied on replication proteins from the host. Large viruses (>140 kbp) have their own RNA-primed replication apparatus often supplemented with processivity factors and sometimes by clamp loaders to increase replication speed and efficiency. The only seeming exception from the latter general pattern was eliminated after finding B-family DNA polymerases in large phiKZ phages. Next, we asked whether the distribution of other viral DNA replication proteins depended on genome size. It turned out that as the genome size increases viruses tend to encode their own replication proteins more frequently. The latter insight led us to a search for "missing" replication components in large genomes. This has resulted in the discovery of singlestranded DNA binding (SSB) proteins in the largest eukaryotic viruses. Surprisingly, these proteins turned out to be homologs of SSB proteins previously thought to be specific for T7-like phages. Another surprise came from the analysis of DNA helicases. We found out that replicative helicases were the most common replication proteins in dsDNA viruses. In addition, our analysis revealed that the component of herpesviral helicase-primase complex (UL8) was a highly diverged and inactivated B-family DNA polymerase. 


\section{MUSCLE TRAITS AND THEIR ADAPTATION TO PHYSICAL TRAINING IN A MOUSE MODEL: ROLE OF GENETIC AND GENOMIC VARIATION}

\section{Audrius Kilikevičius}

\section{Scientific supervisor:}

dr. Arimantas Lionikas,

University of Aberdeen,

Lithuanian Sports University

The dissertation defended:

5 May 2014
The aim of the research was to identify mouse strains with substantial phenotypic differences in skeletal muscle phenotypes at baseline and contrasting in their ability to adapt to endurance training and functional overload. Strains of mice with markedly different phenotypes are the most appropriate model for the exploration of genetic mechanisms underlying phenotypic differences. However, the variation of muscle traits and in particular their response to training are not well examined across the strains. Our studies have established strains with the contrasting muscle traits: muscle weight, fiber count and size, proportion of type I fibers. We also revealed strains with different muscle weight response to endurance training or functional overload. In addition to the classical inbred mouse strains, we used wild derived $\mathrm{PWD} / \mathrm{PhJ}$ strain and BEH, BEL, DUi strains that were selected for divergent body weight, expecting that derivation of these strains may account for genetic and phenotypic diversity. In the previous reports it was determined that $\mathrm{BEH}$ and BEL mouse strains differed by more than three times in the body weight. Therefore they are suitable to investigate the mechanisms underlying this phenotype. In addition to this, we have established their suitability for muscle research. Because the genome sequences of $\mathrm{BEH}$ and BEL strains are not known, we initiate RNA-seq analysis to describe differences of transcribed DNA sequences between them. Also, we estimated differences of the gene expression profile in the muscle tissue between the BEH and BEL strains. The results of the scientific project are important to select appropriate mouse strains to study genetic mechanisms underlying muscle traits and their adaptation to physical training study. 


\section{PECULIARITIES OF CONCATENATION BETWEEN CARDIOVASCULAR FUNCTIONAL INDICES WHILE PERFORMING INCREASING WORKLOAD UP TO INABILITY TO CONTINUE THE TASK}

\section{Vilma Papievienè}

Scientific supervisor:

prof. habil. dr. Jonas Poderys,

Lithuanian Sports University

The dissertation defended:

15 May 2014
The aim of the study was to find out the peculiarities in concatenation between central and peripheral cardiovascular indices under the conditions of increasing fatigue. Novelty of the research is as follows: 1 . It is shown that it is purposeful to distinguish functional and functional state indices in the evaluation of peculiarities of the cardiovascular system under fatigue increase; 2 . The algebraic data co-integration method is usually applied to evaluate the dynamic concatenation of ECG indices. Our study determined that the algebraic data cointegration approach could be used in assessing the dynamic peculiarities of cardiovascular functional indices under fatigue increase; 3. It was found out that the same dynamics of concatenation among cardiovascular functional parameters under fatigue increase was attributed to both endurance and sprint cohorts. The speed of change of concatenation in endurance cohort under physical load is lower; the stable phase of closer concatenation lasts longer and diminishes at the end of workload as compared to the sprint cohort. 


\section{EFFECT OF ANTHOCYANINS ON CARDIAC MITOCHONDRIAL FUNCTIONS AND ISCHEMIA-INDUCED CELL DEATH}

\section{Kristina Škèmienè}

\section{Scientific supervisor:}

dr. Julius Liobikas,

Lithuanian University of Health Sciences

\section{The dissertation defended:}

5 June 2014
A lot of research is carried out with anthocyanins, which are widely prevalent among colored berries, fruits, and vegetables and give them blue, red, violet, and purple colors. It is known that consumption of dietary plants and products rich in anthocyanins can reduce the risk of cardiovascular diseases. This protective effect is related to the antioxidant properties of anthocyanins. We have raised the hypothesis that anthocyanins could protect cardiomyocytes from ischemia / reperfusion-induced cell death reducing cytosolic cytochrome $c$. The aim of this work was to investigate the effect of anthocyanins on heart mitochondrial oxidative phosphorylation and determine what intracellular signaling pathways responsible for cell death are regulated by these compounds. The tasks of the study were the following: 1 . To investigate the direct effect of anthocyanins on rat heart mitochondrial respiration rates; 2 . To determine the ability of anthocyanins to reduce cytochrome $\mathrm{c}$ in vitro; 3 . To determine whether anthocyanins - cytochrome c-reducing compounds - protect heart mitochondria from ischemiainduced mitochondrial dysfunction and ischemia / reperfusion-induced cardiomyocyte apoptosis and necrosis; 4 . To examine whether anthocyanins with high cytochrome-c reducing activity can restore the efficiency of mitochondrial oxidative phosphorylation after ischemia; 5 . To verify whether the effect of the investigated anthocyanins on cardiac mitochondrial function and their protective effect on ischemia / reperfusion-induced damage are not determined by anthocyanin metabolites. 


\section{PHYTOPLASMAS AND THEIR INSECT VECTORS IN LITHUANIA}

\section{Algirdas Ivanauskas}

\section{Scientific supervisor:}

dr. Deividas Valiūnas,

Nature Research Centre

The dissertation defended:

17 June 2014
The aim of the research was to identify the phytoplasmas detected in insects that were found on various phytoplasmainfected plants, and to reveal phytoplasma insect-vectors as well as phytogenetical relationships of identified phytoplasmas. From previous research, we already know a few mostly widespread phytoplasma groups, subgroups, and many of their host plants in Lithuania. The data on potential vectors of these bacteria are very scarce in Lithuania. The identification and research of insect vectors will help to create more effective strategies and systems to fight with phytoplasmal infections. Identification of phytoplasmas and their vectors will provide important data for research of ecology, distribution, origin, epidemiology, and ways of spreading of these pathogens. Such information is beneficial for plant protection institutions and plant growers in Lithuania and neighbouring countries. It will help to ascertain possible invasive insect species and phytoplasma strains in Lithuania. During this research for the first time in Lithuania, we determined possible phytoplasma insect vectors using molecular biology methods. Most of the detected phytoplasma subgroups were found in the identified insect species for the first time in Lithuania and worldwide. Our data on new potential insect vector species extend the spectrum of phytoplasma vectors in our region. Phytoplasmas were detected for the first time in five plant species in Lithuania. We identified in this work one new phytoplasma subgroup for Lithuania and the world, and one new subgroup for Lithuania and their planthosts. New phytoplasma subgroups and their host plants found during this study contribute to biodiversity and distribution research of phytoplasma detected in Europe and worldwide. 


\section{THE ROLE OF EPITHELIAL CELLS NADPH OXIDASE IN THE PATHOGENESIS OF COLON INFLAMMATION}

\section{Rima Ramonaitè}

Scientific supervisor:

prof. habil. dr. Limas Kupčinskas,

Lithuanian University of Health Sciences

The dissertation defended:

30 June 2014
Genetic and functional studies indicated the importance of reactive oxygen species (ROS) induced oxidative stress in the development of chronic inflammatory bowel disease (IBD). NADPH oxidase enzymes (Nox1, Nox2, Nox3, Nox4, Nox5, Duox1 and Duox2) are the important source of ROS in the organism. These enzymes-derived ROS act as intracellular second messengers for a variety of cellular receptor signal transduction pathways, and they play pivotal roles in various biological activities, including host defence, cell growth and differentiation, stimulation of pro-inflammatory genes, and cell death. The epithelial NADPH oxidase isoforms are highly expressed in the colon, particularly in the colon epithelial cells. These enzymes come into close contact with normal and pathogenic bacteria and may play an important role in local innate immune, cell signalling pathways and inflammation in the gut. The aim of this study is to investigate the role of NADPH oxidase of colon epithelial cells in the pathogenesis of colon inflammation during ulcerative colitis and DSS-induced colitis. The results of our study revealed the importance of NADPH oxidase in the pathogenesis of colon inflammation. Moreover, we are the first to show that the treatment with NADPH oxidase inhibitors has a protective effect against the pro-inflammatory action of LPS in human and mice primary colon epithelial cells in vitro. 


\section{INVESTIGATION OF THE INFLUENCE OF BONE MARROW STEM CELLS ON SKIN REGENERATION IN BALB/C MOUSE MODEL IN VIVO}

\section{Giedrè Ramanauskaitė}

\section{Scientific supervisor:}

prof. dr. Genè Biziulevičienè, State Research Institute Center for Innovative Medicine

\section{The dissertation defended:}

3 July 2014
Acceleration of the regeneration process is necessary for severe full-thickness skin injuries, such as burns, trauma or chronic ulcers. The aim of this dissertation was to investigate the influence of bone marrow-derived stem cells on skin regeneration using a full-thickness wound model in BALB/C mouse. Lin ${ }^{-}$cells were isolated and identified. Regenerative properties of purified cells were evaluated in vitro. Wound healing after Lin $^{-}$cells transplantation was examined histologically and cytokine gene expression was determined by quantitative RT-PCR. The results revealed that $\mathrm{Lin}^{-}$population was heterogeneous and contained distinct undifferentiated cell types. In vitro experiments showed that skin tissue extracellular matrix components enhanced proliferation and migration of $\mathrm{Lin}^{-}$cells. Histologic analysis indicated that inhibition of inflammation, re-epithelization, formation of skin appendages and extracellular collagen were most effective after cell transplantation with type I collagen. Quantitative analysis revealed that transplanted Lin $^{-}$cells decreased expression of proinflammatory cytokine TNF- $\alpha$ and increased anti-inflammatory IL-10 expression. Also, gene expression of growth factors TGF- $\beta$ and VEGF, which enhance regeneration, was improved in different healing phases. The results obtained provide additional knowledge for possible therapeutic application of stem/progenitor cells in difficult-to-heal wounds. 


\section{MOLECULAR CHARACTERIZATION OF ESCHERICHIA COLI PRODUCING CTX-M $\beta$-LACTAMASES}

\section{Agnè Giedraitienè}

\section{Scientific supervisor:}

prof. dr. Alvydas Pavilonis,

Lithuanian University of Health Sciences

The dissertation defended:

18 September 2014
Multidrug resistant and CTX-M $\beta$-lactamase-producing clinically important $E$. coli strains are becoming a growing issue not only in hospitals but also in the public all over the world. The treatment of infections caused by these bacteria is difficult and complicated due to a narrow choice of antibiotics. The aim of the study was to determine phenotypic and molecular characteristics of $E$. coli isolates producing CTX-M $\beta$-lactamases and to determine the associations between the blaCTX-M genes and the phylogenetic group, the site of infection, and coresistance in Lithuanian population $E$. coli isolates producing $\beta$-lactamases. The goals were as follows: 1) to determine the frequency of multiresistance among E. coli isolates and the most common multiresistance pattern; 2) to identify E. coli blaCTX-M gene types, their relationship towards antibiotic resistance, evaluate the prevalence frequency of the insertion sequence ISEcp 1 and to determine types of plasmids, responsible for the spread of blaCTX-M genes; 3 ) to determine the frequency of phylogenetic groups and ST131 clone in E. coli isolates; 4) to evaluate the associations between blaCTX-M genes and the phylogenetic group, the site of infection, and coresistance in Lithuanian population $E$. coli isolates producing $\beta$-lactamases. 


\section{TAXONOMY, CHOROLOGICAL COMPOSITION AND TROPHIC RELATIONSHIPS OF THE EURONEMORAL FAUNA OF NEPTICULIDAE (INSECTA, LEPIDOPTERA)}

\author{
Asta Navickaitè \\ Scientific supervisor: \\ doc. dr. Arūnas Diškus, \\ Lithuanian University of Educational Sciences \\ The dissertation defended: \\ 26 September 2014
}

The goal of the dissertation is to present the first taxonomic, chorological and trophic review of the Nepticulidae of the Crimea and Lithuania within the context of the global and European Nepticulidae fauna. There are 19 objectives of the research which are divided into 3 parts: I. General assessment of the Nepticulidae fauna (In this part of the dissertation the general assessment of taxonomic composition and distribution of Nepticulidae fauna was performed within the Earth's biogeographical regions. We estimated the data of trophic relationships among the Stigmella hemargyrella species and performed cladistic analysis). II. The Crimean Nepticulidae within the context of the European Fauna (The taxonomic composition and trophic relationships of the European Nepticulidae were estimated and the chorological analysis was performed. We examinated the scientific material and identified Nepticulidae species of the Crimean fauna. The geographical distribution and chorological groups of the Crimean fauna were identified and the periods of larval activity were defined). III. Taxonimic, chorological and trophic analysis of the Lithuanian Nepticulidae Fauna (In this part we evaluated the taxonomic composition of the Lithuanian Nepticulidae and presented a checklist. We also performed the chorological analysis and compared chorological data on the Nepticulidae fauna of various regions of Lithuania). 


\section{TAXONOMY OF THE NEPTICULIDAE OF CONTINENTAL EAST ASIA (INSECTA, LEPIDOPTERA, NEPTICULIDAE)}

\section{Agnẻ Rociené}

\section{Scientific supervisor:}

prof. habil. dr. Jonas Rimantas Stonis,

Lithuanian University of Educational Sciences

The dissertation defended:

26 September 2014
The object of the doctoral research is one of the most phylogenetically primitive (and thus theoretically one of the most important) taxa of the Lepidoptera order. The distinctive feature of the Nepticulidae family is deep trophic specialization and wide distribution in almost all terrestrial habitats and continents (except the Antarctic) (Puplesis, 1994; Diškus \& Stonis, 2012). Though the family has long been an object of study, the fauna of many regions is still poorly known. East Asia is an important centre of biodiversity and is faunistically related with the European biota. Therefore studies of the East Asiatic Nepticulidae are important for better understanding of the old faunogenetic processes which took place in the Eurasian continent. Furthermore, because of the highly characteristic tendencies of stenophagy, sedentary way of life and endemism, Nepticulidae are among the most suitable tools to characterize the richness of biodiversity, origin and relationships of biomes (or biotas) (Stonis, 2010). However, data on these economically and theoretically important insects are rather poor. 


\section{DEVELOPMENT, OPTIMIZATION AND APPLICATION OF PCR-BASED \\ METHODS FOR MOLECULAR CHARACTERIZATION OF TRANSGENIC INSERTS IN GENETICALLY MODIFIED PLANTS}

\section{Rapolas Spalinskas}

Scientific supervisor:

prof. habil. dr. Juozas Rimantas Lazutka,

Vilnius University

The dissertation defended:

30 September 2014
One of the fastest developing fields of biotechnology in the past three decades is that of genetically modified (GM) plants for industrial applications, as well as food and feed. The European Union (EU) has probably the most rigorous regulations for GMOs in the world and as such, the decisions made by the EU political institutions on regulatory and marketing actions heavily depend on scientific evidence. This doctoral dissertation deals with the molecular biology laboratory methods based on the most popular to date method, polymerase chain reaction (PCR), used in the molecular characterization of the genetically modified organisms (GMOs). When studying the molecular structure of the GMO, two main interests of the nucleotide sequence are as follows: (1) the actual sequence of the transgenic insert, and (2) the plant genomic DNA surrounding the synthetic DNA. Two distinct techniques of the Long Template PCR and Genome Walking were analyzed on the GMO DNA matrices. The LT-PCR was applied to obtain a single uninterrupted fragment containing a full transgenic insert of the selected GM events. The analysis of LT-PCR was continued with the application of a novel PCR additive called carbon nanotubes (CNTs) to investigate the impact of this nanomaterial on the specificity, efficiency and the product yield. The Genome Walking is a technique to obtain unknown DNA fragments adjacent to the known DNA. This doctoral dissertation seeks to explain in detail the development and optimization of the method - Long Template Rapid Amplification of Genomic DNA Ends (LT-RADE) and its application on various GMO DNA matrices. 


\section{FORCE DEPRESSION AFTER MUSCLE SHORTENING IS DEPENDENT ON FATIGUE, POST ACTIVATION POTENTIATION AND MECHANICAL WORK}

\section{Gintarè Dargevičiūtė}

\section{Scientific supervisor:}

doc. dr. Nerijus Masiulis,

Lithuanian Sports University

The dissertation defended:

30 September 2014
The purpose of this research was to analyze the rFD relationship between muscle fatigue and PAP. This data provides an opportunity for new studies to determine how $\mathrm{rFD}$ could be affected by post activation potentiation (PAP) and low-frequency fatigue (LFF). It is a common fact that a short, intense exercise can trigger PAP and muscle fatigue. The most likely explanation for PAP is the phosphorylation of myosin regulatory light chains during the conditioning contractions that increase sensitivity of actin-myosin to $\mathrm{Ca}^{2+}$ released from sarcoplasmic reticulum. Previous research has shown that PAP could be caused not only after a maximum voluntary isometric contraction or tetanic electrical stimulation but also after concentric or eccentric contractions. Therefore we hypothesize that $\mathrm{rFD}$ could depend on PAP. Conclusions: 1$)$ rFD at high $(50 \mathrm{~Hz})$ stimulation frequency and MVC were smaller than at low frequency; 2) rFD depends on low-frequency electrical stimulation but not on high and MVC after eccentric exercise of human quadriceps muscle; 3) rFD after muscle shortening depends on mechanical work during muscle shortening but not on the speed of shortening in fresh and fatigued muscle; 4) rFD depends on PAP and mechanical work during muscle shortening. 


\section{THE EFFECT OF MELATONIN ON THE ANTIBODY PRODUCTION AND LEUKOCYTE MIGRATION IN BALB/C LINE MOUSE}

\section{Vitalij Černyšiov}

\section{Scientific supervisor:}

doc. dr. Irutè Girkontaite,

State Research Institute Center

for Innovative Medicine

The dissertation defended:

14 November 2014
Melatonin is a hormone produced by the pineal gland during the dark time. Light during the night suppresses melatonin production. Melatonin is an important biological body regulator: it controls daily and seasonal biorhythms, glucose metabolism, gonadal activity, cardiovascular system, gastrointestinal tract and immune system activity. There is a lot of scientific information about the immunoregulative properties of melatonin. Melatonin modulates the development of some organs of the immune system, cell differentiation, immune response and cytokine production. The imunomodulatory activity of melatonin is usually determined by the following experimental models: surgical pinealectomy, in vivo treatment with melatonin or in vitro treatment of the immune cells with melatonin. However, during the experiments while keeping animals under constant light conditions, melatonin production was rarely naturally inhibited. For the experiments of this study, the method of constant lighting in the mouse model was applied. Our aim was to artificially evoke shift work conditions in order to find out how the deficiency of melatonin production influences the immune system of the shift workers. The results obtained showed that keeping mouse under constant lighting conditions the homeostasis of the immune system (antibody production, leukocyte and granulocyte migration) was disrupted. Therefore, shift work and its influence on the immune system could be considered as a factor for possible health disorders. 


\section{PERIPHERAL BLOOD NEUTROPHIL AND EOSINOPHIL ACTIVITY DURING ALLERGEN-INDUCED LATE-PHASE AIRWAY INFLAMMATION IN ASTHMA}

\author{
Simona Lavinskienè \\ Scientific supervisor: \\ dr. Jolanta Jeroch, \\ Lithuanian University of Health Sciences \\ The dissertation defended: \\ 19 December 2014
}

There is no doubt that eosinophils and neutrophils are important cells participating in asthma pathogenesis. The most prominent feature reflecting asthma pathogenesis is latephase airway inflammation, which occurs a few hours after allergen inhalation. The worldwide published studies on asthma show that most attention is paid to individual, not complex, functions of neutrophils and eosinophils in the airways. Moreover, associations between peripheral blood neutrophil and eosinophil activity and infiltration of these cells in the airways during asthma have not been completely elucidated yet. There are no data about peripheral blood neutrophil and eosinophil activity during allergen-induced late-phase airway inflammation in asthma patients. The aim of this study was to evaluate peripheral blood neutrophil and eosinophil functional activity during allergen-induced late-phase airway inflammation in asthma. Therefore, a successfully applied specific bronchial allergen challenge model allowed us to evaluate dynamic changes in peripheral blood neutrophil and eosinophil activity $7 \mathrm{~h}$ and $24 \mathrm{~h}$ after bronchial allergen challenge in patients with allergic asthma. Our findings provide new evidence about neutrophil and eosinophil functional activity during allergen-induced late-phase airway inflammation in asthma patients. Our study provides new information about the pathogenesis of allergic asthma. We found that an inhaled allergen activates peripheral blood neutrophil and eosinophil chemotaxis, phagocytosis, generation of ROS and also reduces apoptosis during late-phase airway inflammation in asthma. Furthermore, altered peripheral blood neutrophil and eosinophil functional activity is related to airway neutrophilia and eosinophilia. Changes in peripheral blood neutrophil and eosinophil activity observed in this study could be useful for asthma monitoring and predicting disease progression. 
DIVERSITY AND ECOLOGICAL PROPERTIES OF DOTHIDEOMYCETES AND

SORDARIOMYCETES IN ALLUVIAL BLACK ALDER FORESTS AND PINE

FOREST AFFECTED BY CORMORANTS

\section{Tatjana Iznova}

Scientific supervisor:

doc. dr. Jone Rukšènienè,

Vilnius University

The dissertation defended:

22 December 2014
The aim of the study was to investigate the diversity and ecological properties of Dothideomycetes and Sordariomycetes in the alluvial black alder forests and the pine forest affected by cormorants. For the first time in Lithuania, detailed investigations were carried out on the diversity and distribution of Dothideomycetes and Sordariomycetes in the above-mentioned forests. The checklist of the study fungi was complied. 72 Dothideomycetes and Sordariomycetes species new to Lithuania were identified and original descriptions of their morphology were provided. The influence of abiotic factors on the diversity of woody and herbaceous plants fungi was evaluated for the first time in Lithuania. The results of the study enhanced the knowledge about the distribution of Dothideomycetes and Sordariomycetes in the alluvial forests protected in Europe, which may be used to protect the biologic diversity of these habitats. The properties of the diversity and distribution of studied fungi in the pine forest affected by cormorants allow assessing the impact of the hypertrophication, caused by these birds on the pine forest mycobiota. 


\section{FACTORS INFLUENCING DIFFERENCES BETWEEN REACTION TIME TO STIMULUS ONSET AND OFFSET}

\section{Rugilè Sokolova}

\section{Scientific supervisor:}

prof. dr. Osvaldas Rukšenas,

Vilnius University

The dissertation defended:

28 February 2014
Usually reaction time to stimulus onset is reported as shorter than reaction time to stimulus offset. When stimuli are of very short duration (less than $1 \mathrm{~s}$ ), this difference in reaction time to stimulus onset and offset is explained by visual persistence. For stimuli of longer duration, longer reaction time to stimulus offset is explained by the suppression of automatically activated response to stimulus onset in reaction time to stimulus offset tasks. The aim of this research was to investigate the influence of response-related factors (foreperiod, action effect, premotor and motor reaction time parts and response type) on the difference between reaction time to stimulus onset and offset. With this purpose four experiments were performed. The results revealed that difference between reaction time to stimulus onset and offset depends on the duration of foreperiod - decreases as the foreperiod increases, but only when the tasks of reaction time to stimulus onset and offset have different action effect. When action effect is equalized in both tasks, the difference between reaction time to stimulus onset and offset does not depend on the duration of the foreperiod. Premotor time is shorter in reaction time to stimulus onset than in reaction time to stimulus offset tasks, but motor time does not differ between the tasks. Difference between reaction time to stimulus onset and offset is independent from the type of mechanical response. 


\section{LOW-DOSE IONISING RADIATION EFFECT ON THE \\ ELECTROPHYSIOLOGICAL PROPERTIES OF NITELLOPSIS OBTUSA CELLS}

\section{Olga Sevriukova}

\section{Scientific supervisor:}

dr. Vidmantas Sakalauskas,

Vilnius University

The dissertation defended:

27 June 2014
Nowadays, low-dose ionising radiation can have a significant impact on humans and the environment, since it can occur in daily life from higher natural background radiation, rising anthropogenic pollution, medical, occupational, and accidental exposure. In the present study, it was shown for the first time that low doses of external exposure due to tritium alter membrane electrical properties of Nitellopsis obtusa cells. Since it was also found that Nitellopsis obtusa cells expressed different bioelectrical response to tritium, aluminium and combined aluminium and tritium treatment, tritium could be considered as an important factor in the aluminium phytotoxicity expression. It was also revealed that signals about low-dose ionizing radiation from closed source or radioactive strontium induced effects could be transmitted from an irradiated cell to an unexposed neighbouring cell and cause changes in the bioelectrical activity of a non target cell. These radiation induced bystander effects seem to occur due to signal transduction between two adjoining internodal cells through plasmodesmata. The obtained results showed that electrophysiological investigations could provide a useful tool in assessing the risk from low-dose ionizing radiation to a single plant cell in vivo, and also can be applied in radioecological monitoring of the environment and assessment of radiation exposure for nonhuman biota. 


\section{THE EFFECT OF TRANSCRANIAL MAGNETIC STIMULATION ON BRAIN BIOELECTRICAL ACTIVITY}

\section{Vladas Valiulis}

\section{Scientific supervisor:}

doc. dr. Gytis Svirskis,

Lithuanian University of Health Sciences,

dr. Kastytis Dapšys,

Vilnius University

The dissertation defended:

12 September 2014
Transcranial magnetic stimulation (TMS) is a modern non-invasive method of drug resistant psychiatric disorder treatment. TMS physiology research is hindered by variable, often controversial results. In most studies main attention is being focused on immediate effects after a single TMS procedure rather than the influence of a complete therapy course. It is considered that variability of results in the TMS practice is caused by different stimulation parameters and imprecision of stimulated area placement in the brain. Although TMS therapy is often viewed as a milder alternative to electroconvulsive therapy (ECT), comparative physiological studies of these two methods are very rare. The aim of this study was to evaluate the effect of the rTMS therapy course on bioelectrical brain activity and compare it to an ECT effect. The research included the effect of high and low frequency $(10 \mathrm{~Hz}$ and $1 \mathrm{~Hz})$ TMS on the EEG band power spectrum and auditory evoked potential P300, using both standard and neuronavigated target positioning. TMS evoked EEG changes were also compared to the changes of ECT. Change dynamics after several months of TMS therapy were also measured. The results showed that after TMS therapy the most notable change in the brain occurred in the form of delta power increase. When using standard positioning $10 \mathrm{~Hz}$ TMS evokes more diverse and intense EEG band power spectrum changes than $1 \mathrm{~Hz}$ TMS. Application of neuronavigation system decreases theta and alpha band power changes in the $10 \mathrm{~Hz}$ TMS case. Several months after the TMS therapy delta band power decreased more than theta band power. ECT caused increase of delta and theta band power was several times greater compared to the TMS effect. After TMS therapy decreases of P300 latency and amplitude were observed. Reduction of P300 latency correlated with clinical improvement in depressive symptoms. 


\section{DETECTION OF ENDOGENOUS PORPHYRINS BY MEANS OF SPECTROSCOPY AND MICROSCOPY IN THE CASE OF RHEUMATOID ARTHRITIS}

\author{
Romualdas Rudys \\ Scientific supervisor: \\ doc. dr. Saulius Bagdonas, \\ Vilnius University \\ The dissertation defended: \\ 29 September 2014
}

Rheumatoid arthritis (RA) is an autoimmune disease, which affects $0.5-1.0 \%$ of adults. The aim of this thesis is to study accumulation and localization of endogenous porphyrins by means of spectroscopy and microscopy in an experimental rheumatoid arthritis model and postoperative samples of patients after application of 5-aminolevulinic acid or its methyl ester. The spectroscopic measurements of endogenous porphyrins were performed in synoviocytes, chondrons and cartilage explants of patients with RA or osteoarthritis (OA) and in a rabbit antigen induced arthritis model. The localization of endogenous porphyrins in the synovium and cartilage tissues of rabbit knee joints was determined based on fluorescence spectroscopy, fluorescence intensity and lifetime microscopy, and histology imaging results. The studies showed that selective sensitization of inflamed synovium in the in vitro model may be achieved using ALA and ALA-Me, while in the in vivo model only using ALAMe. Photosensitizer protoporphyrin IX induced by these precursors is accumulated in the cells of synovium and cartilage tissues. The results presented in this dissertation can be used anticipating to apply the sensitization with endogenous porphyrins for diagnostic and therapeutic purposes in the case of rheumatoid arthritis. 


\section{NEURONAL DIFFERENTIATION AND NEUROPROTECTIVE PROPERTIES OF MESENCHYMAL STEM CELLS}

\section{Akvilè Jarmalavičiūtè}

Scientific supervisor:

dr. Gytis Svirskis,

Lithuanian University of Health Sciences

The dissertation defended:

29 September 2014
New stem cell-based therapeutic strategies for human neurological disorders have attracted a great deal of interest in recent years, but clinically useful therapies are still not available for most patients. The main reason for this is insufficient understanding of fundamental molecular processes regulating growth, differentiation, and survival of human neural cells. These issues may be resolved only with adequate and effective in vitro experimental models. During the first part of our study we established a novel three-stage protocol for neural differentiation of SHED cells. SHEDs treated according to our new differentiation protocol gave rise to mixed neuronal / glial cell cultures, which opens new possibilities for in vitro studies of neuronal and glial specification and broadens the potential for the employment of such cells in experimental models and future treatment strategies. The second part of this study was dedicated to investigation of neuroprotective properties of SHED cells. Specifically, we investigated the effects of exosomes and microvesicles derived from SHEDs during 6-hydroxydopamine-induced apoptosis in human dopaminergic neurons. We found that exosomes, but not microvesicles derived from SHEDs grown on laminin-coated microcarriers in a bioreactor, suppress 6-OHDA-induced apoptosis in human dopaminergic neurons. Our results demonstrate that exosomes derived from SHEDs are potential new therapeutic tools against Parkinson's Disease. 


\section{THE EFFECT OF NANOCOMPOSITES ON CANCER STEM CELLS}

\section{Simona Steponkienè}

\section{Scientific supervisor:}

prof. habil. dr. Ričardas Rotomskis,

Vilnius University

The dissertation defended:

30 September 2014
Emerging evidence has shown that the capacity of a tumor to grow and propagate is dependent on a small subset of cells, termed "cancer stem cells". Conventional treatments, however, may miss the cancer stem cells, which have been shown in several tumor types to be more resistant to standard chemotherapeutic agents because the cancer stem cell survives and regenerates the neoplasm. The aim of this study was to investigate the applicability of quantum dots in detection and eradication of cancer stem cells. The properties of stem cells were inestigated in breast, pancreatic, ovarian cancer and melanoma cells. The accumulation and distribution of quantum dots was assessed by the means of laser scanning confocal and fluorescence lifetime imaging microscopy. It was shown that anti-CD44 and quantum dot conjugates were internalized selectively inside CD44+ cells, while anti-CD44 and organic dye FITC conjugates remained attached to the cell membrane for at least 24 hours. Moreover, the complex of quantum dot (QD) and photosensitizer chlorin e6 (Ce6) accumulates inside cells and initiates cell death upon QD-directed exposure of $470 \mathrm{~nm}$ irradiation. These results show the capability of quantum dots not only to detect and internalize stem-like cells but also to carry the therapeutic agent inside cells without losing its activity. 